\title{
Literature Review and Survey of Inventory Control Policy with Various Demand Parameters
}

\author{
Kamal Kumara, Ashok Kumar ${ }^{\text {b }}$, and Meenuc \\ aDepartment of Mathematics, Baba Mastnath University, Rohtak, India \\ E-mail Id: kamalkumar4maths@gmail.com \\ bDepartment of Mathematics, Meerut College, Meerut, India \\ E-mail Id:drakkashyap@hotmail.com \\ cResearch Scholar, Baba Mastnath University, Rohtak, India \\ E-mail Id: sigrohameenu@gmail.com
}

\begin{abstract}
Inventory is the stock of goods and items in any business for the basis of sales and future production. The list may remain in the type of raw material, spare parts, and finished goods. Inventory management assists in many gains in the stock. It helps in sustain the list in a suitable quantity and supplying the same at the right timings. The managers of the firm try to develop different inventory policies to increase the profit of the firm. Different type of demands is the key policies from which manager increases the market and hence make the profit for the structure. In this paper, the latest work in the area of inventory control for various applications is presented.
\end{abstract}

Key Words: Inventory, Increasing demand, Price dependent demand, Stock dependent demand, and Time-dependent demand.

\author{
PAPER/ARTICLE INFO \\ RECEIVED ON: 21/01/2020 \\ ACCEPTED ON: 23/03/2020 \\ Reference to this paper \\ should be made as follows: \\ Kamal Kumar, Ashok \\ Kumar, and Meenu (2020), \\ "Literature Review and \\ Survey of Inventory Control \\ Policy with Various Demand \\ Parameters", Int. J. of Trade \\ and Commerce-IIARTC, Vol. 9, \\ No. 1, pp. 191-199
}


Literature Review and Survey of Inventory Control Policy with Various Demand Parameters

Kamal Kumar, Ashok Kumar, and Meenu

\section{INTRODUCTION}

Operations research is the implementation of the scientific methods and a way of carrying out a particular task to the problem involving the operations of the set-up to distribute those in control of the organization with the best result of the problem. Operations research aims to provide a scientific basis to the decision-maker for problem-solving. Operations research is widely used in defense, industry, agriculture, planning, and LIC. Operations research study generally in one the judgment phase, the research phase, and the action phase. A model in OR may be defined as the representation of reality. It describes a problem with some logical and systematic approach. While designing a model, two different goals usually effect in our judgment:

a. The model may be as definite as realizable.

b. It may be as simple as feasible in solving.

Models may be simplified by changing the nature of variables, modify constraints changing the relationship between variables. The advantages of an operations research study in business may be classified as better control, better structure, better conclusion, and better correlation. It helps to reduce the carrying cost of the stock.

\section{INVENTORY}

Inventory may be described as the stock of products. The list includes raw material, work- inprocess, finished goods, and spare parts. For any business, the stock is kept in existence to reduce the ordering and penalty costs. The aim of maintaining inventory has been regulatory of the considerable cost of set- up, holding, and storing goods. Its paused opportunity cost, additional charge, and storehouse cost. Hence, it is essential to retain an inventory.

Types of Inventory:

a. Fluctuation Inventory: It is produced to reach any emergency of stock.

b. Anticipation Inventory: It is perpetuated to make confident that no client keeps upset by not obtaining the required items.

c. Transportation Inventory: It is necessary for the shipment of products from one location to another and farther to the consumers.

d. Cycle Inventory: It happens that the rate of consumption as the rate of purchasing of production.

e. Decoupling Inventory: It is a safety stock of sorts. It is used in work-in-process goods.

Inventory control is the activity to determine what and how much of different goods are kept in stock. It also controls the time and amount of different products to be obtained. The main conclusion of inventory control is to decrease speculation in the record and establishing that manufacturing does not suggest at that time.

\section{DEMAND}

Demand means the desire of clients or consumers for a particular object or thing. Demand is defined as the number of goods required per unit time. Demand may go annoyed because of the shortage. Demand is divided into dependent and independent. When the demand size is known and fixed is said to be deterministic, and when it is supposed to be a random variable is said to be probabilistic. It depends on different parameters. The demand may be represented as

- Quadratic demand: In a market, when an item started, its demand increases linearly for sometimes, and new items added in the place of this available demand decreases. This form of demand is quadratic demand. The demand

$$
\mathrm{D}(\mathrm{t})=\mathrm{a}+\mathrm{b} \mathrm{t}+\mathrm{ct} \mathrm{t}^{2} \text { where } \mathrm{a}, \mathrm{b}, \mathrm{c}>0 \text { and } \mathrm{a}, \mathrm{b}, \mathrm{c} \text { are constants and } \mathrm{t} \text { is time. }
$$


- Cubic demand: The demand rate is based on the time-dependent cubic function. The demand is given by

$D(t)=a+b t+c t^{2}+d t^{3}, a \geq 0, b \neq 0, c \neq 0, d \neq 0$ and $a, b, c, d$ are constants and $t$ for time.

- Exponential demand: The demand rate is either an exponentially increasing function of time or exponential decreasing function of time. The exponentially growing demand rate is

$\mathrm{D}(\mathrm{t})=\mathrm{a} \mathrm{e}^{\mathrm{bt}}$, where $\mathrm{a}$ and $\mathrm{b}(\mathrm{a}>\mathrm{b})$ are constants, and $\mathrm{t}$ is time.

The exponential decreasing demand rate is

$\mathrm{D}(\mathrm{t})=\mathrm{a} \mathrm{e}^{-\mathrm{bt}}$, where $\mathrm{a}$ and $\mathrm{b}$ are constants, and $\mathrm{t}$ is time.

- Linear demand: Indirect order, order may be increase or decrease. A demand equation expresses need as a function of the unit price. The demand

$\mathrm{D}(\mathrm{t})=\mathrm{a}+\mathrm{bt}, \mathrm{a}>0, \mathrm{~b}><0$ and $\mathrm{t}$ is time.

- Multivariate demand: In this demand is the distinctive combination of time and on-hand inventory level. The demand is

$D(t)=a+b t+c I(t), a>b, a, b, c>0$ and $t$ is time.

- Stock dependent demand: The demand is taken to be based on the seller's stock level. Without cooperativeness, the seller establishes its order to increase its gain, which is commonly less than the manufacturer's economic production quantity. The demand is

$\mathrm{D}(\mathrm{t})=\mathrm{a}+\mathrm{bI}(\mathrm{t}), \mathrm{a}, \mathrm{b}>0$ and $\mathrm{I}(\mathrm{t})$ is inventory level at time $\mathrm{t}$.

- Ramp type demand: In this type of application, the cost of items runs with the time up to the distinct point in time and then wholly steady and yield to be constant, and at last demand, function declines to zero and the items depart from the market in their life cycle. The demand is

$$
D(t)=\left\{f(u) \text { if } t_{i}>u \text { and } f\left(t_{i}\right) \text { if } t_{i}<u \text { for } i=1,2,3 \ldots\right\} \text { where } t_{i} \text { is time of deterioration. }
$$

\section{INVENTORY MODELS FOR DEMAND WITH VARIOUS PARAMETERS: THE LATEST TREND}

The commonly known reality that the need for any items depends upon its selling price. In a supermarket, it is observed that the display of customer goods attracts more customers and produces higher demand. Inventory experts have discussed the ELS with different needs and came into results with definite exciting facts. Baker and Urban (1988) formulated a deterministic inventory system with stock dependent demand rate. Datta and Pal (1990) worked on decaying items and presented a model with an inventory level. Shortages are permitted in this model. Demand is a linear function. The order is subject to the stock level. Shortages are backlogged for the cases of finite and infinite perceptions. Padmanabhan and Vrat (1995) studied an EPQ model for unresistant and delicate products. Demand is stock dependent. The selling price is based on the stock level. Bhunia et al. give an inventory model with lot size for decaying items in $\mathbf{1 9 9 8 .}$ This model is a lot-size subject to replenishment cost. Demand has a linear tendency. Bhunia et al. again studied on inventory model and extended his work with two levels of storage in 2001. For a fixed time, demand is a linear function. It is based on time-dependent demand. Benkherouf et al. (2004) proposed a note on an inventory model. This model is used for deteriorating items. The rate is subject to stock level and varies with time. Zhou and Yang established an inventory model with two-warehouse in 2005. The level of good influenced demand. Shortages were not permitted. The process and movement cost for shifting products from RW to OW were subject to transported costs. The average gain of the result should be decreased by obtaining the best replenishment schedule. Gor and Shah (2006)have proposed an EOQ model under the impact of inflation on decline items. The permissible delay in payment is allowed. The price of goods 
Literature Review and Survey of Inventory Control Policy with Various Demand Parameters

Kamal Kumar, Ashok Kumar, and Meenu

determines the rate. Disgusted a simple way of the algorithm to find the best result. Pal et al. (2007) formulated a genetic algorithm for the best policy on partly integrated manufacturing and marketing for a firm that makes only one product. The rate is controlled by selling cost, quality of the item, and marketing price. Soni and Shah explored an inventory model to find the best ordering policy and the following payment schedule in 2008. The rate is conditional on the stock level. Shah and Pandey (2009) developed an inventory model to find the perfect policy for ordering. The price is based on several advertisements and presentations of goods.

Jaggi et al. discussed an inventory model with two warehouses for deteriorating goods in 2010. The rate of deterioration of products is separate in the warehouses. The demand is subject to price sensitivity. They have a junction that good were released into a tremendous amount from RW to OW. This model is appropriate for both the selling cost and ordering quantity. Yang et al. (2010) formulated a model for deteriorating products under the effect of inflation. The assumed rate is dependent on stock. It is developed that the penalty cost increases, a gain of organization reduce. Singh et al. developed an inventory model for deteriorating items where demand is based on the present stock level in 2011. The market is a linear function and depends on immediate stock - this model used for electronic components, domestic goods, and fashionable clothes. The effect of permissible delay in payments was taken into account. Bhunia and Shaikh established an inventory model for single deteriorating products with two different storage conditions in 2011.

The rate of the item is based on constant time, selling cost, and some advertisements. The replenishment rate is infinite. Shortages are permitted and partially backlogged. The demand for items increases with the increase in the number of ads that are directly proportional to the number of ads. Yadav et al. (2012) applied the genetic algorithm in a fuzzy environment (purchase cost, investment amount, and storehouse capacity) to a model for decaying items. Demand is based stock available in the store. Shortages are not permitted.

The demand for details is linear, dependent on the inventory level at the OW warehouse. An inventory model for time-varying deterioration with increasing demand rate was established by Goswami et al. in 2012. This model is derived with finite replacement rate and unequal length of the cycle time. The associated cost of the system is minimized. Demand is increasing quarterly quadratically with time and production rate. The assumption of shortages is not permitted. Increasing values of parameter find more applications in the market, which shows the reduction of the total cost of the whole system. Singh and Dem (2012) studied a two- warehouse manufacturing model for decline items. Demand is determined by time. The objective of this work is to determine the maximum total profit and the corresponding optimum decision variables. Yang and Chang (2013) developed an inventory model for decline items under partial backlogging. The supplier offers a permissible delay in payments. The demand rate is deterministic at a constant rate of units per unit time. Shortages are permitted. The complete replenishment cycle is reactive to set-up and selling costs. Kumar et al. projected an inventory model under the impact of inflation for deteriorating items in 2013. Shortages are permitted and partial backlogged. Demand is subject to linear time parameters and stock levels.

In OW, time-varying linear deterioration and RW Weibull distributed deterioration was studied. This study applies to food grains. The demand for food items rises with time for a finite time. Singh and Pattnayak developed an EOQ model for deteriorating items with linear demand patterns and variable deterioration rate in 2013. In this study, there is an assumption of shortages and partial backlogging. The concept of the work is to propose an excellent policy that minimizes the average cost. 
Kumari et al. again proposed an inventory model with two different warehouses under the result of inflation and the time value of money in 2014. Deteriorating items have different demand rates. This work is done for both with or without shortages. The price of things is a combination of both time and on-hand stock. Jaggi et al. proposed an inventory model with two different warehouses having different preserving facilities in 2014. A single deteriorating item will be taken in this paper. The location of keeping stock has a different preserving policy. Demand is to be continuously considered. Khurana (2015)projected a two-warehouse model for a deteriorating item under the impact of inflation.

The demand rate is deterministic - the price based on time. The present study of the paper found out total gain per unit time to boost for the first cycle. Dutta (2015)developed a two-warehouse fuzzy inventory model considering cubic demand as a function of time, holding cost, ordering cost, and back-ordering cost to be blurred in nature. Shortages are allowed in the owned warehouse. Sharmila and Uthayakumar explored an inventory model with a fuzzy parameter for degenerate products in 2015. The concept of shortages and fully backlogged is taken in this work. The demand rate is an exponential function of time. The deterioration rate was constant. The optimum solutions of the fuzzy model were defuzzied into the signed distance method will increase the total gain. Tayal et al. established an EPQ model with an exponential demand rate for non-instantaneous decaying elements in 2015. It is an integrated production inventory model. Holding cost is based on time. The demand rate is exponential, and the production rate is a function of the demand rate. Shortages are not allowed. This study gives assistance to minimize the total cost. Singh et al. proposed an economic order quantity model for deteriorating products with trade credit period in 2016. The demand is based on the current stock. The aim of this paper has been the development of a high-power set to control the optimal preservation cost, shortage period, and best total cost under the nature of trade credit and variable ordering cost in which the products are deteriorating in quality. The preservation technology is used for keeping the items. Kumar and Kumar (2016)developed an inventory model with the effect of learning and salaries worth on deteriorating items with capability constraints under partial backlogging. The demand rate is based on current stock. We are in favor of giving shortages and backlogging demand rates determined by the period of stock out.

The price of learning impact increases, and the total inventory cost decreases because the variety of shipments will increase. Singh and Rathore (2016) presented an inventory model for worsening items in a fuzzy environment with a non- instantaneous deterioration rate. This model can be used in cases of fruits, vegetables, cosmetic products. The demand rate is a linear function of the instant stock level. Shortages are allowed and partially backlogged under the result of inflation. The brief of the study is to observe the best solution for the total amount function.

Palani and Maragatham (2017) proposed an inventory model in a fuzzy environment for timedependent worsen items. The lead time is non-zero. The paper presents retailers in structure to decide their EOQ and the cycle time for products having inventory dependent demand rate. The demand rate is an essential function in the total carrying cost and determining the optimal ordering quantity. Saha and Chakrabarti (2017) developed a model for deteriorating products in a fuzzy environment with supply chain production. Demand is taken as a linear price dependent. The signed distance method and graded mean integration method have been formulated for defuzzification. We find out the total amount decreases with the corresponding worth of cycle length by using the signed distance method. The cycle time is to reduce accord to the total amount by using a graded mean integration method for defuzzification. 
Literature Review and Survey of Inventory Control Policy with Various Demand Parameters

Kamal Kumar, Ashok Kumar, and Meenu

Rastogi et al. (2017) developed an inventory model for deteriorating items with two-warehouse. Shortages are supported to be partially backlogged. Cycle time is also fluctuating. The study aims to determine the quantity and time of order, which can maximize the average cost of the structure. The demand rate is a function of selling price Reddy, and Venkateswarlu(2018) studied the optimum inventory policies under the time-dependent quadratic demand rate for twowarehouse. The total cost of inventory system increase (decrease) with the increase (decrease) in initial demand, set-up cost, and carrying value of own- warehouse. Rathore and Singh (2018) proposed a two-warehouse model with preservation technology investment and advertisement dependent demand over a finite time horizon. The maximized period, number of advertisements, cost associated with preservation technologies, and the total cost function is well explored to present perfect inventory control system. This study is ideal for organization trading women's apparel, jeans, leather bags. A two -warehouse model with partially lost sales is again developed by Singh and Agarwal (2018) for lifetime deterioration and inflation with Weibull distribution with an increase. Demand rate is an exponential and increasing function of time.

In our model, stored product value will decay after some time, not immediately. This model is very useful in cloth business, real state, marts, or any large scale and marketing of electronics. A fuzzy two-warehouse model for a single deteriorating product is proposed by Indrajitsingha $\boldsymbol{e t}$ al. (2019). Demand is based on selling price. Shortages are allowed and partially backlogged with subject to the condition on the duration of waiting time up to the arrival of next lot. We observed that an uncertain nature of the system parameters, the total average cost decreases in the fuzzy model as compared to the crisp model. A credit policy approach in a two- warehouse model for deteriorating items is presented by Panda et al. (2019).Demand is based on some advertisements, prices, and goods.

Shortages are partially backlogged. The numbering of advertisements is fixed for a year. The proposed work is highly non- linear. Bishi et al. (2019) proposed a two-warehouse inventory model for non- instantaneous decay items with an exponential rate under different dispatching policies. Shortages are permitted and fully backlogged. The sale, the low-cost storage, a large amount of demand under such a condition one may choose to obtain huge products that occur the problem of keeping.

\section{CONCLUSION}

In this paper, we work with the various demand that affects the inventory level. So, some researchers suggest that the distributor may show each item in large amounts to make higher demand. But this emerges no problem of capacity helping for every product and investment requirements effecting from the enlarged stock quantity. Here most of the aspect of application has been expressed, and related literature survey has been presented. Both crisp and fuzzy models are reviewed in this study. From the above analysis, a model with various demand surcharge stock dependent demand, selling price demand, ramp type demand has scope in supermarkets; however, success depends on the accuracy of the evaluation of the input variables.

\section{REFERENCES}

[1]. Agarwal A., Rani S., Singh S. R. (2018)- Two warehouse inventory model for lifetime deterioration and inflation with exponential demand and partially lost sales. International Journal of Pure and Applied Mathematics. 118(22), 1253-1265.

[2]. Baker R. C. and Urban T. L. (1988)- A dependent deterministic inventory system with an inventory- level-dependent rate. Journal of Operational Research Society.39,1823-1831. 
[3]. Bhunia A. K. and Maiti M. (1998)- A two-warehouse inventory model for deteriorating items with a linear trend in demand and shortages. Journal of Operational Research Society. 49(3), 287-292.

[4]. Bhunia A. K. and Shaikh A. A. (2011)- A two-warehouse inventory model for deteriorating items with time-dependent partial backlogging and variable demand dependent on marketing strategy and time. International Journal of Inventory Control and Management. 1(2),95-110.

[5]. Bhunia A. K., Jaggi C. K., Sharma A. and Sharma R. (2014)- A two-warehouse inventory model for deteriorating items under permissible delay in payment with partial backlogging. Applied Mathematics and Computation. 232, 1125-1137.

[6]. Bishi B., Behera J. and Sahu S. K. (2019)- Two-warehouse inventory model for non instantaneous deteriorating items with exponential demand rate. International Journal of Applied Engineering Research. 14(2), 495-515.

[7]. Datta T. K. and Pal A. K. (1990)- A note on inventory model with inventory level dependent demand rate. Journal of Operational Research Society. 41, 971-975.

[8]. Dem H. and Singh S. R. (2012)- A two-warehouse production model with quality consideration. Procedia Engineering. 38, 3242-3259.

[9]. Dutta P. and Choudhary P. D. (2015)- Fuzzy based two- warehouse inventory model for deteriorating items with cubic demand and different fuzzy cost parameters. International Journal of Engineering Research and General Science. 3(5), 209-218.

[10]. Gor R. and Shah N. (2006)- An EOQ model for deteriorating items with price dependent demand and permissible delay in payments under inflation. Research.43, 376-388.

[11]. Indrajitsingha S. K., Samanta P. N., and Misra U. K. (2019)- A fuzzy two- warehouse inventory model for a single deteriorating item with selling price dependent demand and shortage under partial backlogged condition. International Journal of Applications and Applied Mathematics. 14(1), 511-536.

[12]. Jaggi C. K., Aggarwal K. K. and Verma P. (2010)- Two warehouse inventory models for deteriorating items when demand is price sensitive. International Journal of Operational Research. 7(4), 530-551.

[13]. Kar S., Bhunia A. K. and Maiti M. (2001)- A deterministic inventory model with two levels of storage, a linear trend in demand, and a fixed time horizon. Computer and Operations Research. 28,1315-1331.

[14]. Khurana D. (2015)- Two warehouse inventory model for deteriorating items with timedependent demand under inflation. International Journal of Computer Applications. 114(7), 34-38.

[15]. Kumar N. and Kumar S. (2016)- Effect of learning and salvage worth on an inventory model for deteriorating items with inventory dependent demand rate and partial backlogging with capacity constraints. Uncertain Supply Chain Management. 4, 123-136.

[16]. Kumar N., Singh S. R. and Tomar J. (2013)- Two warehouse inventory models with multivariate demand and K- release rule. Procedia technology. 10,788-796.

[17]. Kumari N. and Kumari R. (2014)- Two warehouse inventory models with K-release rule, multivariate demand, and lost the sale with time value of money. International Journal of Computational and Applied Mathematics. 4(1), 83-94.

[18]. Padmanabhan G. and Vrat P. (1995)- An EOQ model for perishable items under stock dependent selling rate. Journal of Operational Research Society. 86, 281-292. 
[19]. Pal P., Bhunia A. K. and Goyal S. K. (2007)- On optimal partially integrated production and marketing policy with variable demand under flexibility and reliability consideration via genetic algorithm. Applied Mathematics and Computation. 188,525-537.

[20]. Palani R. and Maragatham M. (2017)- Fuzzy inventory model for time-dependent deteriorating items with lead time stock dependent demand rate and shortages. International Journal of Development Research. 7(10), 1588-1599.

[21]. Panda G. C., Khan M. A. A., and Shaikh A. A. (2019)- A credit policy approach in a twowarehouse inventory model for deteriorating items with price and stock dependent demand under partial backlogging. International Journal of Industrial Engineering. 15, 147-170.

[22]. Rastogi M., Singh S. R., Kushwah P. and Tayal S. (2017)- Two- warehouse inventory policy with prices dependent demand and deterioration under partial backlogging. Decision Science Letters, 6, 11-22.

[23]. Rathore H. and Singh A. (2018)- Two-warehouse inventory models with preservation of technologies investment and advertisement dependent demands over a finite time horizon.Journal of physics: conference series, 1139, p. 1-9.

[24]. Rathore H. and Singh S. R. (2016)- Two warehouse inventory model with preservation technology investment and partial backlogging. Scientia Iranica. 23(4), 1952-1958.

[25]. Reddy M. S. and Venkateswarlu R. (2018)- Optimal inventory policies for a two- warehouse inventory model under time-dependent quadratic demand rate. Global Journal of Pure and Applied Mathematics. 14(8), 1011-1027.

[26]. Saha S. and Chakrabharti T. (2017)- A fuzzy inventory model for deteriorating items with linear price dependent demand rate in a supply chain. International journal of the fuzzy mathematical archive. 13(1), 59-67.

[27]. Sett B. K., Sarkar B. and Goswami A. (2012)- A two-warehouse inventory model with increasing demand and time-varying deterioration. Scientia Iranica. 19(6), 1969-1977.

[28]. Shah N. H. and Pandey P. (2009)- Deteriorating inventory model when demand depends on the advertisement and stock display. International Journal of Operational Research. 6(2), 33-44.

[29]. Sharmila D. and Uthayakumar R. (2015)- An inventory model for deteriorating items involving fuzzy with shortages and exponential demand. International Journal of Supply and Operations Management. 2(3), 884-904.

[30]. Shilpy T., Singh S. R., Sharma R., and Singh A. P. (2015)- An EPQ model for noninstantaneous deteriorating items with time-dependent holding cost and exponential demand rate. International Journal of Operational Research. 23(2), 145-162.

[31]. Singh S. R., Khurana D. and Shilpy T. (2016)- An EOQ model for deteriorating items having dependent stock demand with trade credit period and preservation technology. Uncertain supply chain management. 4, 29-42.

[32]. Singh S. R., Kumari R. and Kumar N. (2011)- A deterministic two warehouse inventories model for a deteriorating item with stock dependent demands and shortage under the condition of permissible delays. International Journal of Mathematical Modelling and Numerical Optimization. 2(4), 357-375.

[33]. Singh T. and Pattnayak H. (2013)- An EOQ model for deteriorating items with linear demand, variable deterioration, and partial backlogging. Journal of Service Science and Management. 6, 186-190. 
[34]. Soni H. and Shah N. H. (2008)- Optimal ordering policy for dependent stock demand under a progressive payment scheme. European Journal of Operational Research. 184, 91-100.

[35]. Yadav D., Singh S. R. and Kumari R. (2012)- An inventory model of deteriorating items with two warehouses and stock dependent demand using genetic algorithm in a fuzzy environment. Yugoslav Journal of Operations Research. 21(2), 1-29.

[36]. Yang H. L. and Chang C. T. (2013)- A two-warehouse partial backlogging inventory model for deteriorating items with permissible delay in payment under inflation. Applied Mathematical Modelling. 37, 2717-2726.

[37]. Yang H. L., Teng J. T. and Chetan M. S. (2010)- An inventory model under inflation for deteriorating items with stock dependent consumption rate and partial backlogging shortages. International Journal of Production Economics. 123, 364-370.

[38]. Zaid T. B. and Benkherouf L.(2004)- A note on an inventory model for deteriorating items with stock dependent and time-varying demand rates. Computers and Operations Research.31,223-240.

[39]. Zhou Y. W. and Yang S. L. (2005)- A two-warehouse inventory model for items with stock level dependent demand rate. International Journal of Production Economics. 95, 215-228. 